\title{
Construcción de prototipo de CANSAT para toma de imágenes aéreas para detección de zonas de vegetación en agricultura de precisión
}

| Fecha de recibido: 22 de febrero del 2021 | Fecha de aprobación: 3 de junio del 2021 |

Sebastián Augusto Zapata Gil

Estudiante, Ingeniería Aeroespacial

Universidad de Antioquia Colombia

Grupo de Investigación en Ciencia y

Tecnología Aeroespacial (ASTRA) Rol del investigador: experimental y escritura

https://orcid.org/0000-0002-9695-4532

$\triangle$ sebastian.zapatag1@udea.edu.co

Jorge M. Zamora Vélez Ingeniero Electrónico

Docente, Ingeniería Aeroespacial Universidad de Antioquia Colombia

Grupo de Investigación en Ciencia y

Tecnología Aeroespacial (ASTRA) Rol del investigador: docente y escritura https://orcid.org/0000-0003-2646-2257

\jmario.zamora@udea.edu.co
Sebastián

León Serna

Estudiante, Ingeniería Aeroespacial Universidad de Antioquia Colombia

Grupo de Investigación en Ciencia y Tecnología Aeroespacial (ASTRA) Rol del investigador: experimental y escritura https://orcid.org/0000-0002-2870-2608

$\triangle$ sebastian.leons@udea.edu.co

Juan José Mejía González

Estudiante, Ingeniería Aeroespacial Universidad de Antioquia Colombia

Grupo de Investigación en Ciencia y Tecnología Aeroespacial (ASTRA) Rol del investigador: experimental y escritura https://orcid.org/0000-0003-2624-9798 凶 juan.mejiag1@udea.edu.co
Nicolás Buriticá Isaza

Estudiante, Ingeniería Aeroespacial Universidad de Antioquia Colombia

Grupo de Investigación en Ciencia y Tecnología Aeroespacial (ASTRA) Rol del investigador: experimental y escritura https://orcid.org/0000-0003-0723-3053

$\triangle$ nicolas.buritica@udea.edu.co

Davinson Arsuis González Jaramillo

Estudiante, Ingeniería Mecánica

Universidad de Antioquia Colombia

Grupo de Investigación en Ciencia y Tecnología Aeroespacial (ASTRA) Rol del investigador: experimental y escritura https://orcid.org/0000-0002-1115-7199

$\triangle$ arsuis.gonzalez@udea.edu.co

Cómo citar este artículo: Zapata-Gil, S., León-Serna, S., Buriticá-Isaza, N., Zamora-Vélez, J., Mejía-González, J., \& González-Jaramillo, D. (2021). Construcción de prototipo de CANSAT para toma de imágenes aéreas para detección de zonas de vegetación en agricultura de precisión. Ciencia y Poder Aéreo, 16(2), 11-28. https://doi.org/10.18667/cienciaypoderaereo.709 


\section{Construcción de prototipo de CANSAT para toma de imágenes aéreas para detección de zonas de vegetación en agricultura de precisión}

Resumen: En este artículo se presenta el diseño del CANSAT Heliospectrum ${ }^{1}$, desarrollado para su aplicación en percepción remota y análisis de imágenes para competir en el concurso anual realizado por la Sociedad de Sistemas Electrónicos y Aeroespaciales (AESS), capítulo Colombia. El equipo Helios, desarrollador del CANSAT, hace parte del grupo de investigación ASTRA de la Universidad de Antioquia. El diseño se realizó siguiendo las restricciones impuestas por el concurso, en las cuales el picosatélite debía asemejarse a una radiosonda con transmisores, componentes electrónicos, sensores con medición de aceleraciones, presión atmosférica, temperatura, campos magnéticos y aptitud para volar a 1.000 metros de altura (como mínimo), caer libremente y aterrizar con la ayuda de un paracaídas. Así mismo, cumple con los requerimientos necesarios para hacer del CANSAT una plataforma multipropósito con énfasis en percepción remota para aplicación en agricultura de precisión. Se implementó una cámara RGB como carga útil que, con ayuda de un algoritmo de análisis de imágenes que implementa el Excess Green Index (ExG) y el espacio de color Hue, Saturation, Value (HSV), permitió obtener resultados cualitativos de índices de vegetación. El CANSAT está conceptualizado en cinco subsistemas: computadora de vuelo, telemetría, estructura, descenso y recuperación, y potencia. En la aviónica del picosatélite se encuentran componentes principales como el microcontrolador Teensy 3,5, GPS GY-NEO6MV2, IMU GY89 y en el sistema de recuperación un paracaídas expulsado con un servomotor. El prototipo de CANSAT fue fabricado y probado con éxito por el equipo, resultando ganador de la categoría "Cóndores" de la competencia CANSAT Colombia de la AESS.

Palabras clave: análisis de imágenes; CANSAT; pico satélite; percepción remota; agricultura de precisión.

Abstract: This article presents the design of the CANSAT Heliospectrum, developed for remote sensing and image analysis, which participated in the annual competition held by the Society for Aerospace and Electronic Systems (AESS), Colombia Chapter. The team Helios, developer of the CANSAT, is part of ASTRA Research Group at the University of Antioquia (Colombia). The equipment was designed following the restrictions imposed by the competition, which stated that the picosatellite must resemble a radiosonde with transmitters, electronic components, sensors that measure accelerations, atmospheric pressure, temperature, magnetic fields, and besides being able to fly at a height of at least 1,000 meters, fall freely and land with the help of a parachute. The design meets the requirements to make of this CANSAT a multipurpose platform focused on remote sensing for its application in precision agriculture activities. An RGB camera was implemented as payload. This component allowed obtaining qualitative results of vegetation indices through an image analysis algorithm that implements the Excess Green Index (Exg) and the Hue Saturation Value (HSV) color scale. The CANSAT is conceptualized in five subsystems: flight computer, telemetry, structure, descent and recovery, and power. The avionics of the picosatellite includes main components such as the Teensy 3,5 microcontroller, GPS GY-NEO6MV2 and IMU GY-89, while the recovery system has a parachute that is ejected with a servomotor. A prototype of the CANSAT was manufactured and successfully tested by Helios, being awarded the "Condors" category at the AESS CANSAT Colombia competition.

Keywords: image analysis; CANSAT; picosatellite; remote sensing; precision agriculture.

Resumo: Este artigo apresenta o desenho do Heliospectrum CANSAT desenvolvido para sua aplicação em percepção remota e análise de imagens para competir no concurso anual realizado pela Sociedade de Sistemas Eletrônicos e Aeroespaciais (AESS), capítulo Colômbia. A equipe Helios, desenvolvedora do CANSAT, faz parte do grupo de pesquisa ASTRA da Universidade de Antioquia. O projeto foi realizado seguindo as restrições impostas pela competição, em que o picossatélite deveria se assemelhar a uma radiossonda com transmissores, componentes eletrônicos, sensores com medição de acelerações, pressão atmosférica, temperatura, campos magnéticos e capacidade de voar a 1.000 metros de altura. (no mínimo), queda livre e pouse com a ajuda de um paraquedas. Além disso, atende aos requisitos necessários para fazer da CANSAT uma plataforma polivalente com ênfase em sensoriamento remoto para aplicação em agricultura de precisão. Uma câmera RGB foi implementada como uma carga útil que, com a ajuda de um algoritmo de análise de imagem implementa o Excess Green Index (ExG) e o Hue, Saturation, Value (HSV) espaço de cores, permitiu obter resultados qualitativos dos índices de vegetação. O CANSAT é conceituado em cinco subsistemas: computador de vôo, telemetria, estrutura, descida, recuperação e potência. Na aviônica do picossatélite existem componentes principais como o microcontrolador Teensy 3.5, GPS GY-NEO6MV2, IMU GY- 89 e no sistema de recuperação um paraquedas ejetado com servomotor. O protótipo CANSAT foi fabricado e testado com sucesso pela equipe, resultando vencedor da categoria \&quot;Condores\&quot; da competição CANSAT Colômbia da AESS.

Palavras-chave: análise de imagens; CANSAT; picossatélite; percepção remota; agricultura de precisão. 
Colombia es uno de los países con más potencial de expansión del área agrícola en el mundo. De acuerdo con el Fondo Nacional para el Financiamiento del Sector Agropecuario (Finagro, 2021), ocupa el puesto 25 de 223 países en dicho potencial. Pese a ello, también es uno de los países con más riesgo de exposición a invasiones de plagas, según la Portafolio (Duque-Cardona et al., 2020). A partir de esta información, se identificó la necesidad del país de sumarse a las nuevas tecnologías que trae consigo la industria 4.0, dentro de las cuales se destaca el origen de las tecnologías de agricultura de precisión (Trivelli et al., 2019). Dicha área busca solucionar los problemas que se presentan en los cultivos por medio del análisis de imágenes tomadas desde las alturas, con el fin de identificar, entre muchas otras cosas, enfermedades presentadas en las plantas (Candiago et al., 2015; Metternicht, 2003). Estas imágenes pueden ser tomadas con satélites, vehículos aéreos tripulados, y, más recientemente, con vehículos aéreos no tripulados. Estos últimos suelen ser preferidos sobre los demás debido a que permiten obtener imágenes de alta resolución a bajo costo (Honrado et al., 2017).

Una alternativa poco convencional a estos sistemas es el uso de picosatélites CANSAT (Anchino et al., 2019), que consisten en pequeños artefactos del volumen y forma de una lata de gaseosa, que contienen electrónica y sensores dedicados a la toma y procesamiento de datos de vuelo provenientes del entorno, cuyo propósito consiste en emular físicamente satélites artificiales reales (European Space Agency [ESA], s. f.). A diferencia de las otras tecnologías mencionadas, estos son de fácil desarrollo y hacen uso de componentes tipo Commercial Off-the-Shelf (COTS) que, además de ser de muy bajo costo, son de fácil adquisición.

EI CANSAT es un sistema de carácter experimental y práctico, orientado al cumplimiento de tareas asociadas a vuelto suborbital atmosférico de baja altitud. Su desarrollo implica la integración de diferentes aspectos de tipo estructural, mecánico, electrónico y de software. Estas características lo hacen idóneo como plataforma ágil y económica para la realización de diversas tareas, así como para el aprendizaje de diferentes habilidades técnicas en la ingeniería que incorporan la metodología STEM (Baran et al., 2019). De esta manera, es el campo aeroespacial de los más beneficiados por esta metodología, debido a su potencial interdisciplinar, al bajo costo que suponen los proyectos con este modelo y a su complejidad reescalada (English \& King, 2015).

En ese sentido, el presente artículo propone el desarrollo de un prototipo de CANSAT basado en las necesidades de su uso para sondeos en agricultura de precisión de bajo costo y de su adaptación para la participación en la competencia AESS CANSAT Colombia 2020 (Cabuya, 2021). El CANSAT tiene como propósito ser usado para registrar imágenes de áreas agrícolas, y adicionalmente, realizar mediciones ambientales y atmosféricas. Para tal objetivo, el texto se organizó de la siguiente manera: primero se llevó a cabo una revisión de literatura de los trabajos realizados con este tipo de sistemas, a fin de comprender su potencial y sus beneficios en esta área en particular. Después se establecieron los requerimientos en función de los objetivos de misión derivados de las necesidades discutidas del problema, así como de la competencia en la que se participa. Luego se describe el sistema a detalle, dividiéndolo en los segmentos de carga útil, plataforma o vehículo, y la estación terrena, donde se profundizará en los detalles técnicos de la solución propuesta para el CANSAT, para pasar a ilustrar el proceso de prototipado e integración asociados con el proceso de manufactura de la estructura, ensamble y conexión de componentes y puesta en funcionamiento. Una vez hecho esto, se presentan las pruebas realizadas enfocadas a componentes donde además son discutidos los resultados. Por último, se presentan las conclusiones y observaciones finales.

\section{Revisión de Literatura}

En años recientes una gran cantidad de trabajos alrededor del uso de sistemas CANSAT han sido desarrollados. Pese a no ser un artefacto de explotación comercial, cuenta con una gran cantidad de antecedentes en su uso y aplicaciones de tipo experimental en el entorno académico y educativo. Esencialmente 
son empleados como herramientas para la enseñanza en áreas STEM en amplia gama de niveles académicos (Anchino et al., 2019), en instituciones de educación básica se usan para explicar de manera práctica e interactiva temas asociados a la física, además de enseñar conceptos básicos de electrónica y programación (Cabuya, 2020), mientras que a nivel universitario, es usado en programas de ingeniería para darle a los estudiantes un acercamiento al diseño y desarrollo de una misión espacial (Universidad Nacional Autónoma de México, s. f.). En general pueden ser usados como elementos de bajo costo para instruir a estudiantes en todo el ciclo de desarrollo de sistema. Esto es particularmente importante en áreas como la ingeniería aeroespacial en donde se lidia con diferentes disciplinas técnicas, que normalmente se encuentran asociadas a otras ramas específicas en las cuales el acceso a la tecnología puede ser inasequible o altamente costoso (Rodríguez et al., 2021).

Dentro de este mismo entorno académico, múltiples propuestas para realizar actividades productivas asociadas con monitoreo ambiental, climatológico y meteorológico han sido desarrolladas y sugeridas demostrando la gran incursión que han tenido este tipo de tecnología debido a su bajo costo y componentes de fácil acceso (Jaramillo \& Briñez, 2019). De hecho, para estas aplicaciones los CANSAT llevan carga útil asociada a diferente instrumentación que censa el entorno, e incluye, por ejemplo, variables de temperatura, humedad y presión. Asimismo, algunos miden la concentración de gases en la atmósfera tal como el $\mathrm{CO}_{2}$-de sumo interés debido a su considerable contribución a la contaminación ambiental- (Faroukh et al., 2019). De igual manera, los sensores de radiación UV también son empleados en estas plataformas a fin de obtener mejores registros de esta variable debido a la imprecisión que puede darse en tierra (Bhad \& Akant, 2019). Además de ser útiles para monitorear su intensidad, la cual puede afectar la salud humana, perjudicar a las plantas y afectar su crecimiento (Carrasco-Ríos, 2009); por lo cual es pertinente conocer sus valores en el área donde se realiza la toma de imágenes para agricultura de precisión.

Por otro lado, la agricultura de precisión es un campo de amplio potencial en Colombia, al ser un país de gran producción agrícola. Actualmente, la base de la agricultura de precisión es obtener imágenes satelitales que pueden alcanzar un precio bastante elevado tratándose de imágenes de alta resolución. Para la toma de estas imágenes son propuestos Vehículos Aéreos No Tripulados (UAV) como plataformas para realizar estas tareas, ya que por su versatilidad, son apropiados para resistir diversas condiciones ambientales (Parody \& Zapata, 2018). En este sentido, es previsible esperar que las características y atributos del CANSAT puedan ser igualmente explotadas en esta área.

Al desarrollar este objetivo, se utilizó la técnica de percepción remota que se define como "una disciplina basada en ciencia y tecnología que permite desarrollar, capturar, procesar y analizar imágenes, junto con otros datos físicos de la Tierra, obtenidos desde sensores en el espacio, sensores aerotransportados y con sensores que capturan datos de mediciones in situ" (Centro de Investigación en Ciencias de Información Geoespacial [CentroGeo], s. f.). En esencia, se trata de una observación del terreno mediante un plano cenital.

Así bien, además de las aplicaciones en agricultura que se plantearon, la percepción remota puede usarse para cartografiar las actividades humanas y naturales; monitorear procesos físicos; evaluar y mitigar los desastres; vigilar los cambios temporales en la cobertura terrestre; derivar el patrón y monitoreo de procesos de estacionalidad de cuerpos de agua y expansión del medio urbano construido en regiones del país; monitorear parámetros biofísicos de los bosques; detectar fosas clandestinas; así como estimar población en áreas pequeñas y desarrollar catastro en 3D, entre otros usos (CentroGeo, s. f.).

De igual modo, existen diversas propuestas de CANSAT que emplean dispositivos de cámara para la toma de imágenes con el fin de obtener información del microclima usando sensores infrarrojos (Molla, 2018) e integrando sistemas de apuntado para enfocar una zona de interés (Tjandra, 2020), de allí que puedan ser adaptados para este fin integrando software de procesamiento de imágenes.

Sin embargo, pese a los antecedentes mencionados no existe un número significativo de trabajos 
específicos respecto al empleo de CANSAT en el área de agricultura de precisión. Lo cual presenta una oportunidad y foco de investigación.

\section{Metodología}

Tomando como referencia el proceso de ingeniería de misiones espaciales (Wertz et al., 2011), se empleó una metodología de diseño iterativo, partiendo del conocimiento de los aspectos generales del proyecto que permiten identificar los objetivos y restricciones, definir un concepto de misión explorando diferentes alternativas, y finalmente, establecer los requerimientos que retroalimentarán el proceso de diseño. Además, se aplicaron estrategias de prototipado rápido usando tecnologías COTS y procesos de manufactura accesibles como la impresión 3D.

Cabe mencionar que tanto el proceso de diseño como su ejecución, se realizó en el marco de la pandemia, por lo tanto, la metodología se adaptó al trabajo virtual con sesiones de reuniones recurrentes en las que se discutió el diseño conceptual y posteriormente se realizaron pruebas preliminares.

\section{Objetivos de la misión}

EI CANSAT tiene como objetivo primario:

- Tomar fotografías en áreas agrícolas para un posterior procesamiento de datos que revelen índices de vegetación usando tecnologías COTS de bajo costo.

Como objetivos secundarios se tienen:

- Diseño multipropósito que permita incluir diferentes sensores que brinden capacidades específicas según se requiera en futuras aplicaciones.

- Medir las variables atmosféricas.

- Registrar la actitud de vuelo del vehículo.

\section{Requerimientos}

Para orientar de manera correcta el diseño es preciso identificar los requisitos que debe satisfacer el CANSAT con el fin de cumplir sus objetivos, al igual que acatar los lineamientos que se estipulan en el concurso CANSAT Colombia 2020 (Cabuya, 2021). En la tabla 1 pueden evidenciarse los diferentes requerimientos divididos en funcionales, operativos y restricciones.

Tabla 1

Requerimientos y restricciones de la misión

\begin{tabular}{|c|c|}
\hline Requerimiento & Descripción \\
\hline Funcional & $\begin{array}{l}\text { - Medición de variables de actitud de vuelo } \\
\text { (aceleración, velocidad angular). } \\
\text { - Medición de variables ambientales (rayos UV, } \\
\text { humedad, temperatura, presión, intensidad } \\
\text { de campo magnético). } \\
\text { - Registro y almacenamiento de fotografías de } \\
\text { resolución aceptable para el procesamiento } \\
\text { de imágenes. } \\
\text { - Capacidad de incorporar sensores } \\
\text { adicionales usando protocolos UART, } \\
\text { I2C o SPI. }\end{array}$ \\
\hline Operativos & $\begin{array}{l}\text { - Almacenamiento a bordo. } \\
\text { - Transmisión de datos a una estación terrena. } \\
\text { - Alcance mayor a } 1.000 \text { metros entre el } \\
\text { vehículo y la estación terrena. } \\
\text { - Uso de un paracaídas para recuperar } \\
\text { el CANSAT. }\end{array}$ \\
\hline Restricciones & $\begin{array}{l}\text { - Peso máximo } 500 \text { gr. } \\
\text { - Dimensiones estándar de lata de refresco } \\
\text { de } 350 \mathrm{~mL} \text {. } \\
\text { - Costo inferior a los } 250 \text { USD. }\end{array}$ \\
\hline
\end{tabular}

Fuente: elaboración propia.

\section{Concepto de misión}

El factor de forma CANSAT permite una gran variedad de perfiles de vuelo, ya que se tiene la posibilidad de alojar el satélite en diferentes vehículos como globos, drones y cohetes, debido a su reducido volumen y bajo peso. Sin embargo, se optó por una misión conceptual con un cohete como vehículo portador del CANSAT con el fin de cumplir con los requerimientos de la competencia y evaluar las diferentes capacidades operativas del CANSAT en cuanto a la toma y envío de datos con la estación terrena y el despliegue del paracaídas como sistema de recuperación. El perfil de vuelo se divide en cinco momentos, como se ilustra en la figura 1.

De este modo el vehículo permite al CANSAT describir una trayectoria semiparabólica dentro de la atmósfera. A lo largo de esta trayectoria se toman todos 
los datos necesarios por los diferentes sensores con los que va equipado el vehículo para la medición de variables atmosféricas.

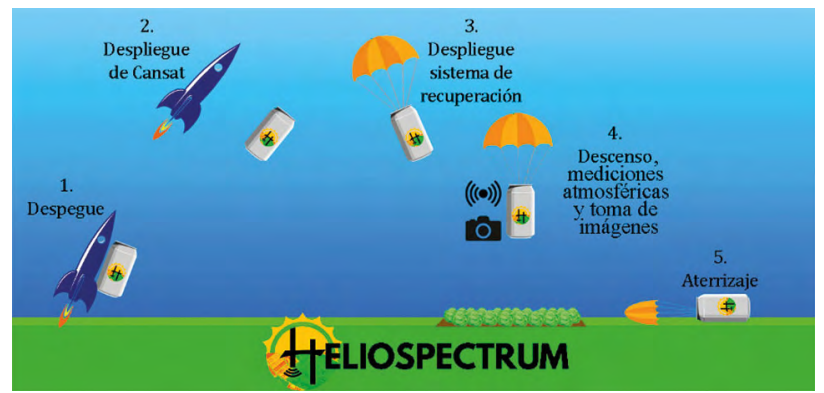

Figura 1. Perfil de vuelo

Fuente: elaboración propia.

Luego del despegue del CANSAT se adquiere altura hasta llegar al punto máximo de la trayectoria o apogeo, y es aquí donde se libera el CANSAT del vehículo lanzador para iniciar la fase de descenso, donde se activa el mecanismo que eyectará el paracaídas y el CANSAT seguirá con el descenso hasta el aterrizaje y su recuperación. En esta última fase toma el registro de fotografías para la percepción remota de la superficie, ya que el CANSAT contará con una mayor estabilidad respecto a su etapa de ascenso, y una vez en tierra, se enviará una señal a la estación terrena para confirmar el aterrizaje.

En la figura 2 se muestran cómo están conformados algunos de los subsistemas y los respectivos protocolos de comunicación utilizados. A continuación, se ampliarán generalidades sobre cada uno y algunos motivos para la selección de los componentes que los conforman.

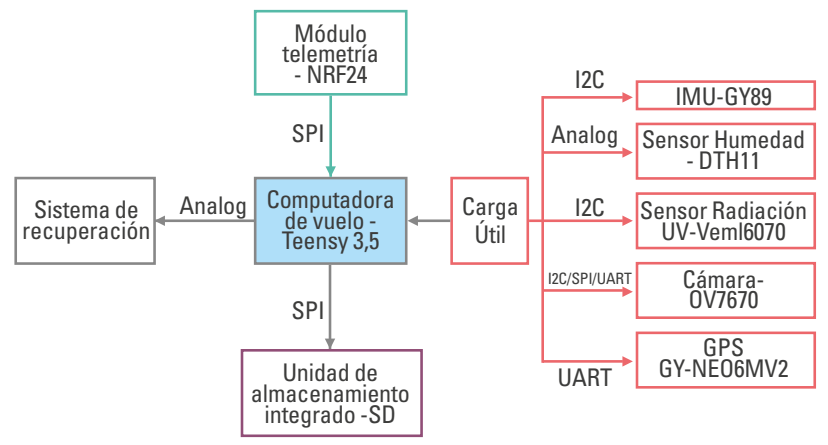

Figura 2. Diagrama de arquitectura general del sistema Fuente: elaboración propia.

\section{Carga útil}

Los objetivos de la misión centrada en la toma de imágenes para detección de vegetación junto con otras asociadas al monitoreo ambiental son cumplidos por la carga útil, el conjunto de instrumentos dedicados a tomar datos y medir diferentes variables físicas.

El corazón de la carga útil es el sensor de imagen responsable del registro fotográfico de la zona de interés en cuestión. Para este propósito es seleccionada una cámara basada en el sensor OV7670 de 30fps y una resolución de 640×480 píxeles en modo VGA (figura 3). Las imágenes obtenidas serán procesadas posteriores a la misión.

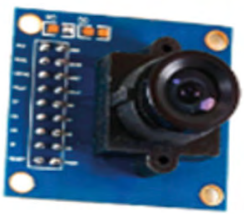

Figura 3. Cámara OV7670

Fuente: OmniVision Technologies Inc.

Así mismo, se cuenta con sensores secundarios a fin de tomar datos de variables atmosféricas de importancia en la agricultura de precisión. Estos incluyen un sensor analógico de humedad DHT11 (figura 4a), que mide la humedad relativa del entorno, y un sensor rayos UV VEML6070 (figura 4b), que arroja la intensidad de luz ultravioleta de longitudes de onda entre los 320 y $410 \mathrm{~nm}$.

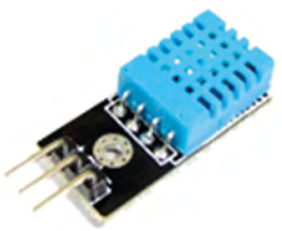

Figura 4a. Sensor de humedad

Fuente: Mouser Electronics (s. f.).

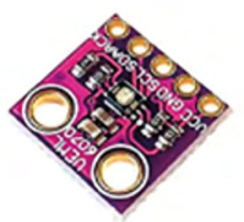

Figura 4b. Sensor Rayos UV

Fuente: Vishay Semiconductors (2019). 


\section{Procesamiento de imágenes}

Las imágenes obtenidas son procesadas luego de la misión donde se busca detectar la vegetación presente a través del reconocimiento de variaciones de tonos verdes en la imagen. Para lograrlo se implementó un algoritmo de procesamiento de imágenes que sigue un proceso similar al propuesto, en el cual la imagen RGB original es transformada al espacio Hue, Saturation, Value (HSV) (Yang et al., 2015). En ese punto se diferencian los objetos pertenecientes a vegetación y los que no.

Inicialmente, se busca calcular el índice Excess Green (ExG) así:

$$
E \times G=2 G-R-B
$$

Donde $\mathrm{G}$ representa el píxel color verde, $\mathrm{R}$ el rojo y $\mathrm{B}$ el azul. En este caso, el índice ExG se utiliza para convertir en negro los píxeles que componen la imagen RGB cuyas tonalidades no tienen valores de verde, y convierte en blanco aquellos píxeles que en efecto sí contienen tonalidades de este último color.

Más tarde, la imagen resultante generada por el índice ExG es llevada al espacio de color HSV. Este espacio presenta una gran ventaja, ya que la imagen final revela los objetos blancos corregidos al verde, permitiendo así un análisis de las condiciones y salud del cultivo y de cada planta individualmente.

\section{Plataforma}

La plataforma del CANSAT constituye todo aquello dedicado a soportar el funcionamiento y operación de la carga útil, se divide en diferentes subsistemas como navegación, computadora de vuelo, transceptor, baterías, sistema de descenso y recuperación, estructura y estación terrena.

\section{Navegación}

Se incorporó el sensor de navegación IMU GY-89 (figura 5a), que integra el barómetro, el cual permite medir la altura mediante la diferencia de presiones atmosféricas con una precisión de 0,5 m; también, posee el giroscopio L3GD20H y el acelerómetro LSM303D, los cuales permiten obtener mediciones de campo magnético (rumbo), velocidades angulares y aceleraciones. La integración de estas variables determina la actitud de vuelo del vehículo representada por los ángulos de Euler.

Por último, y con el propósito de determinar la ubicación geográfica del CANSAT, se contó con el GPS GY-NEO6MV2 (figura 5b), el cual cumple con requerimientos de volumen ( 23 milímetros de ancho por 30 milímetros de alto), precisión (seis cifras decimales en latitud y longitud) y bajo costo.

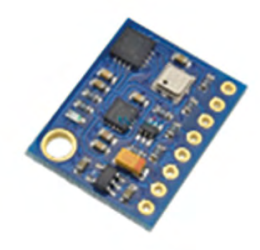

a.

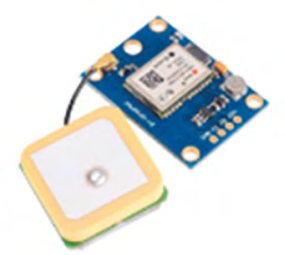

b.
Figura 5. Sensores de navegación

Fuente: U-blox (2017).

Nota. (a) IMY GY 89; (b) GPS GY-NEO6MV2.

\section{Computadora a bordo}

Esta unidad es la responsable de gestionar, administrar y controlar todas las operaciones y procesos involucrados durante toda la misión. Para ello se empleó el microcontrolador Teensy 3,5 (PJRC, s. f. a), el cual, a pesar de tener una capacidad de procesamiento superior a la mayoría de los microcontroladores convencionales (Sparkfun, s. f.), presentó como principal motivo de elección una gran disponibilidad de pines General Purpose Input/Output (GPIO) y el hecho de que esta tarjeta incorpora una unidad de almacenamiento SD, como se evidencia en la zona superior de figura 6 , lo cual permitió ahorrar conexiones y espacio en la estructura.

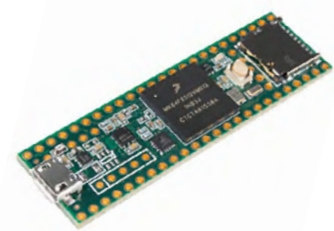

Figura 6. Módulo Teensy 3,5

Fuente: PJRC Electronic Projects. 
Asimismo cumplió su propósito al permitir programar las instrucciones cómodamente en el IDLE de Arduino (PJRC, s. f. b), además de cumplir con los requerimientos funcionales y operacionales ya descritos. De esta manera, el algoritmo desarrollado (figura 7) comenzó inicializando las variables necesarias donde serán almacenados los datos de interés, posteriormente se inicializaron los sensores haciendo uso de los respectivos protocolos de comunicaciones como se presentó en la figura 2. Después de que se verificara que todos los sensores están correctamente conectados, el algoritmo entra en un bucle principal (loop) donde se empezarán a leer los datos de las variables; no obstante, el GPS requiere un trato diferente a los demás sensores de la carga útil, ya que necesita de un tiempo de espera para realizar la conexión con los satélites. Por tal motivo, es necesario un ciclo interno con un tiempo máximo de un segundo, en el cual se evalúa la recepción de un nuevo dato de posición.

Por otro lado, y no menos importante, la computadora de vuelo debe recurrir a los datos proporcionados por los sensores para detectar dos momentos cruciales del perfil de vuelo de la misión: el apogeo -momento de mayor altitud-y el aterrizaje del CANSAT.

El apogeo es necesario para iniciar la activación del sistema de descenso. Para esto es imprescindible conocer la altura del CANSAT en todos los momentos de la misión, lo cual es posible gracias al barómetro BMP180. De esta manera, el algoritmo encargado de esta función compara los datos de altura de la medición inmediatamente anterior y activa el sistema cuando se lee un cambio negativo, lo que significa que el CANSAT ya pasó por su punto máximo de altura.

El envío de la señal de confirmación de aterrizaje se realiza vez el CANSAT se encuentra en tierra para iniciar su recuperación. Esta condición se detecta gracias al acelerómetro L3GD20, en el cual el algoritmo verificará el cambio de aceleraciones en los tres ejes durante un tiempo considerable, si este cambio permanece en un valor aproximado a cero se determina que el CANSAT está en reposo y se marca el final del ciclo principal.

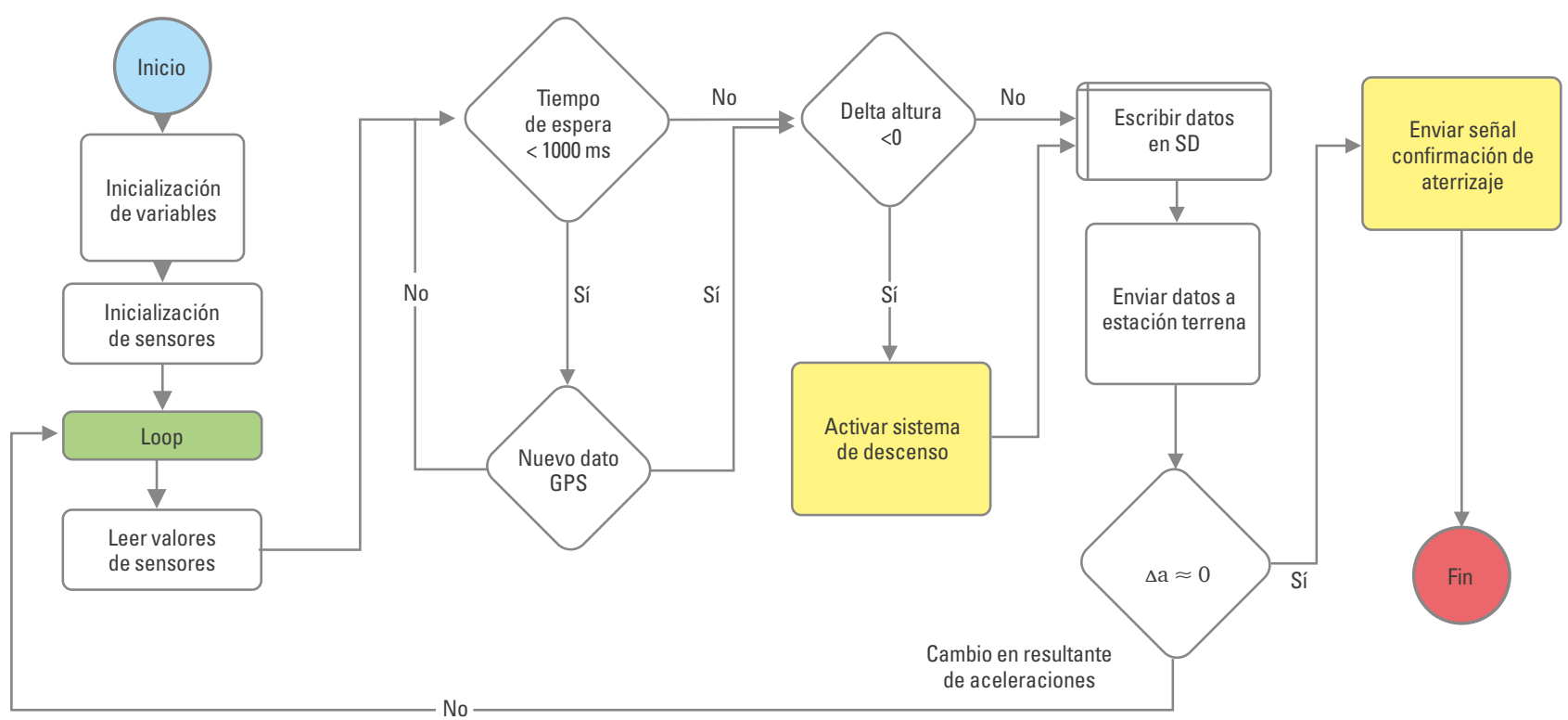

Figura 7. Diagrama de flujo algoritmo computadora de vuelo Fuente: elaboración propia. 
Por último, la computadora de vuelo debe encargarse de la escritura de datos en el módulo SD incorporado. Al igual que debe gestionar el envío de dichos datos a través del módulo transceptor.

\section{Transceptor}

Su objetivo es recopilar y enviar los datos medidos por los sensores en tiempo real a la base terrena de forma inalámbrica. Este subsistema consta de dos módulos transceptores nRF24L01 (figura 8), uno integrado en el CANSAT, el cual actúa como transmisor, y otro en la base terrena, que sirve de receptor. Si bien este módulo no es tan robusto como lo pueden ser el módulo LoRa o el Xbee, muy usados en aplicaciones CANSAT, cumple con los requerimientos de transmitir datos a un kilómetro de distancia y es de bajo costo. El módulo nRF24L01 opera a una frecuencia de $2,4 \mathrm{GHz}$, con velocidad de envío de datos de 0,250, 1 y 2 Mbps y trabaja con el protocolo de comunicación SPI.

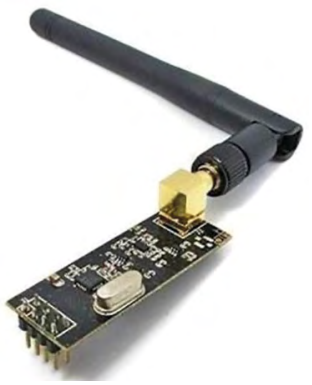

Figura 8. Módulo transceptor nRF24L01

Fuente: Nordic Semiconductor (2008).

\section{Batería}

El suministro de potencia principal corresponde a una batería de polímero de litio (LiPo) de 3,7 V $1.200 \mathrm{mAh}$, la cual se encarga de proveer energía eléctrica a la computadora de vuelo, al módulo GPS y al módulo de comunicaciones - debido a que estos dos últimos requieren una corriente de operación mayor a la proporcionada por los pines GPIO del microcontrolador-. Los demás componentes son alimentados por dichos pines sin problema, gracias a que su tensión de operación es de 3,3 V, suministrados por el regulador de tensión interna del Teensy.
A su vez, el servo motor que activa el sistema de recuperación y descenso requiere de una tensión y una corriente superior a la que podía proporcionar el microcontrolador. Por lo tanto, se emplearon dos baterías LiPo en serie de 3,7 V $200 \mathrm{mAh}$ para suministrar una tensión de 7,4 $\mathrm{V}$ que permitieron al servo motor funcionar correctamente. El esquema de la distribución de potencia eléctrica mencionado puede evidenciarse en la figura 9.

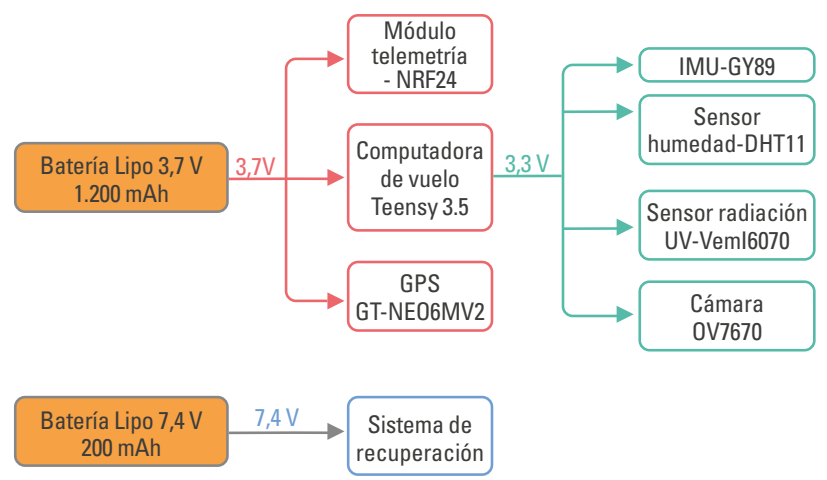

Figura 9. Esquema de suministro de potencia eléctrica

Fuente: elaboración propia.

\section{Descenso y recuperación}

EI CANSAT debe retornar a tierra a salvo manteniendo su integridad y la del equipo a bordo, con el fin de asegurar su reutilización y la preservación del producto de la misión. Asimismo, debe asegurarse su recuperación física desde la ubicación de aterrizaje una vez la misión haya concluido.

\section{Paracaídas}

Como requerimiento se establecía el uso de un paracaídas como el sistema apropiado para hacer descender y recuperar al CANSAT. Para garantizar que los componentes internos sobrevivan el impacto con el terreno se definió una velocidad terminal de $5 \mathrm{~m} / \mathrm{s}$, significativamente inferior a la recomendación de la Agencia Espacial Europea, la cual es de $11 \mathrm{~m} / \mathrm{s}$ para vehículos con sistema de recuperación incluido (ESA, s. f.). Para lograr la velocidad deseada con el paracaídas se empleó la teoría aerodinámica haciendo uso de la ecuación 2. 


$$
V=\sqrt{ } \frac{2 w}{C_{D} \rho A}
$$

Donde $C_{D}$ es el coeficiente de arrastre, $W$ peso del CANSAT en $\mathrm{kg} \mathrm{m} / \mathrm{s}^{2}$, $\rho$ es la densidad del aire en la ciudad de lanzamiento en $\mathrm{kg} / \mathrm{m}^{3}, A$ el área efectiva en $\mathrm{m}^{2}$ y V es la velocidad terminal en $\mathrm{m} / \mathrm{s}$.

El lugar de referencia para el lanzamiento es Bogotá. Con esto, se tiene una densidad del aire igual a $1.255 \mathrm{~kg} / \mathrm{m}^{3}$, una velocidad terminal aproximada de $5 \mathrm{~m} / \mathrm{s}$ y un peso de $3,43 \mathrm{~N}$. A partir de estos datos se obtiene un diámetro requerido para el paracaídas de alrededor $500 \mathrm{~mm}$, como se muestra en la figura 10 .

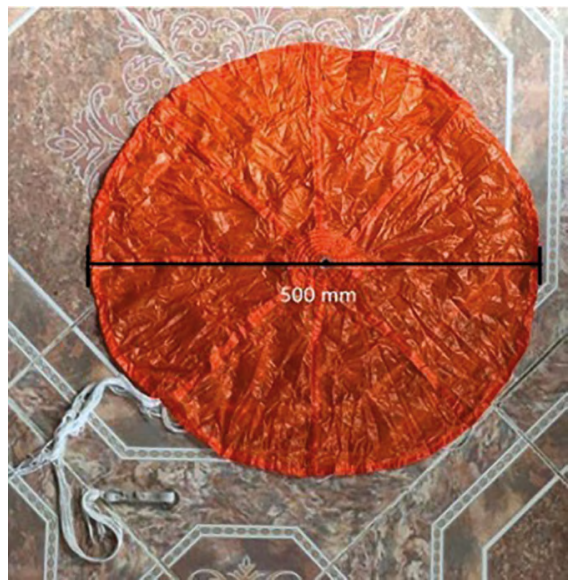

Figura 10. Paracaídas para el descenso

Fuente: elaboración propia.

El paracaídas está fabricado en ripstop nylon, una tela muy resistente a la tracción y muy maleable, lo que brinda seguridad. Además, dicho material es blando lo que permite doblar el paracaídas de tal modo que se aproveche al máximo el espacio disponible (Tortora, 1996).

\section{Mecanismo de eyección}

El mecanismo de eyección es el encargado de expulsar el paracaídas del interior del CANSAT. Para esto se consideraron varias opciones, en primer lugar, estaba usar una bahía cargada con pólvora negra y encenderla con un estopín de manera que los gases ejercieran presión en el contenedor del paracaídas que lo obligaran a ser eyectado. La segunda opción considerada fue el uso de una cápsula de dióxido de carbono que usa el mismo principio de gases a presión para expulsar el paracaídas. Sin embargo, estas opciones eran relativamente complicadas y usaban mucho espacio, por lo tanto, fueron descartadas. De ese modo, la solución seleccionada se basó en el uso de un resorte helicoidal cónico a compresión. La elección de la forma del resorte se debe a que este resorte cónico cuenta con una tasa de compresión casi constante durante su acción, y además, permite un óptimo manejo del espacio ocupando poca altura (General Wire Spring Company, s. f.). Al ser comprimido, el resorte almacena energía en forma elástica y a través de un servomotor que gira un disco con levas en el interior, como se ilustra en la figura 11. Las levas abren las extremidades de sujeción de la bahía del paracaídas, liberando la parte superior de la estructura y permitiendo al resorte en compresión liberar su energía y sacar el paracaídas de una forma eficaz (figura 12).

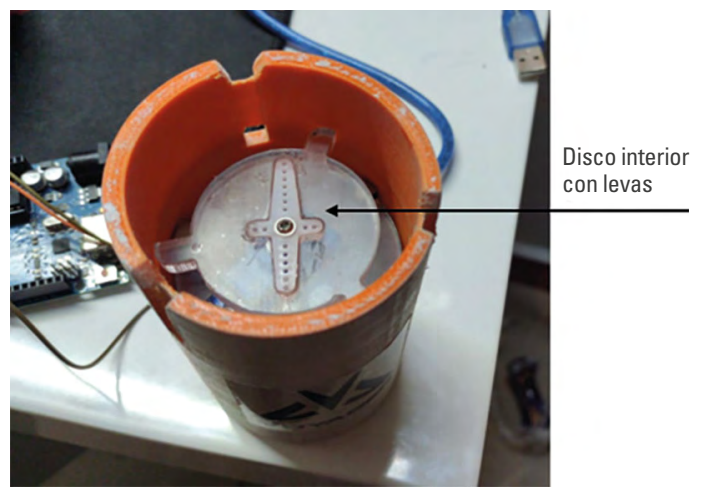

Figura 11. Sistema de eyección de paracaídas sin ensamblar Fuente: elaboración propia.

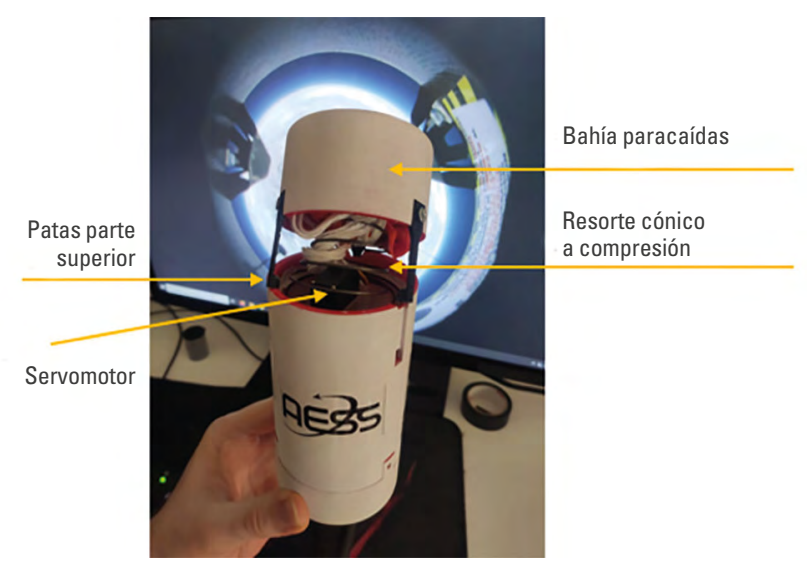

Figura 12. Sistema de eyección de paracaídas ensamblado Fuente: elaboración propia. 


\section{Estructura}

Sumado a lo anterior, la estructura fue una parte fundamental para el desarrollo del proyecto, ya que en ella se aloja toda la aviónica del dispositivo y se debían acomodar todos los componentes, por lo cual debía brindarles soporte físico y protección de manera permanente. De forma inicial se planteó una estructura simple con tres elementos axiales (columnas) y dos plataformas transversales, la cual se refinó a medida que avanzaba el proceso de diseño e integración del CANSAT (figura 13) hasta obtenerse una estructura definitiva, en la que se incluyeron secciones y carcasas para los sistemas internos (comunicación y telemetría, sensores y aviónica, y potencia eléctrica), el sistema de recuperación requirió del diseño de una estructura especial para su funcionamiento, explicado detalladamente en la sección anterior. En la figura 11 y figura 12 puede apreciarse cómo se integró el mecanismo de eyección y la estructura de la que dependía su funcionamiento.

Las modificaciones a la estructura se realizaron con el objetivo de que todos los componentes electrónicos se acomodaran correctamente dentro del CANSAT con las dimensiones propuestas. En principio, la estructura se modificó para integrar el sistema de eyección del paracaídas; la carcasa exterior se diseñó teniendo en cuenta la eyección del sistema de recuperación, y, a partir de allí se hizo una parte inferior cerrada y una tapa superior, que posteriormente sería desprendida, para finalmente poner una pequeña tapa inferior con el fin de facilitar la acomodación de los componentes electrónicos; además de brindarle una posición correcta a la cámara y la antena, las cuales sobresalen por la parte inferior del CANSAT. Hechas estas modificaciones, el dispositivo estaba en capacidad de obtener las imágenes y tener la mejor comunicación posible con la base terrena.

Los componentes de la estructura interna fueron fabricados con madera MDF y acrílico. Las carcasas fueron elaboradas con manufactura aditiva e impresión 3D, los detalles de la evolución del diseño estructural se muestran en la figura 13.

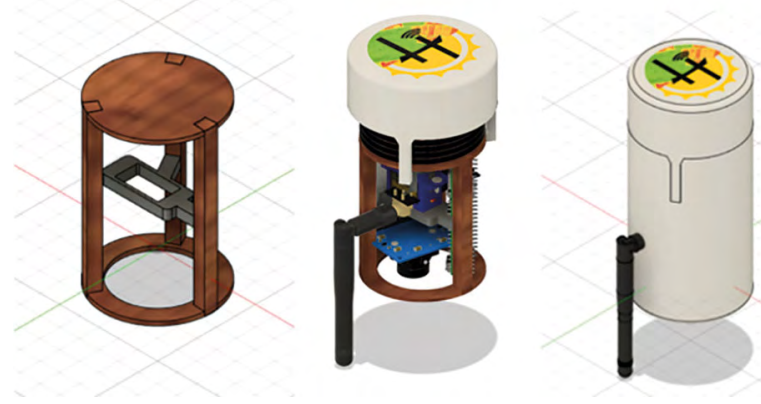

Figura 13. Diseño estructural del CANSAT

Fuente: elaboración propia.

Nota. Diseño inicial simplificado (izq.), diseño definitivo con carcasa de la zona de eyección (centro) y CANSAT con carcasas completas (der.).

Se optó por el uso de PLA para la fabricación de la carcasa al ser el material que mejor se ajustó al perfil de la misión por brindar una buena resistencia mecánica frente a esfuerzos de tracción y frente a impactos, además de ser un material comercial y asequible, por lo que se ajustó al presupuesto del equipo. Adicional a esto, las extremidades que mantendrían la tapa superior unida al resto de la carcasa fueron fabricadas en PET, ya que gracias a sus propiedades aporta ductilidad a las piezas. Así mismo, para obtener el mejor rendimiento mecánico de este material en el momento de la eyección del paracaídas, fue sometido a un tratamiento térmico que consistía en elevar la temperatura de las piezas hasta alcanzar el punto de transición vítrea para aumentar aún más su ductilidad, y así permitir que se deformaran sin romperse y que pudieran volver a su forma inicial luego de aplicado el esfuerzo. Este proceso se llevó a cabo en un horno, como se muestra la figura 14.

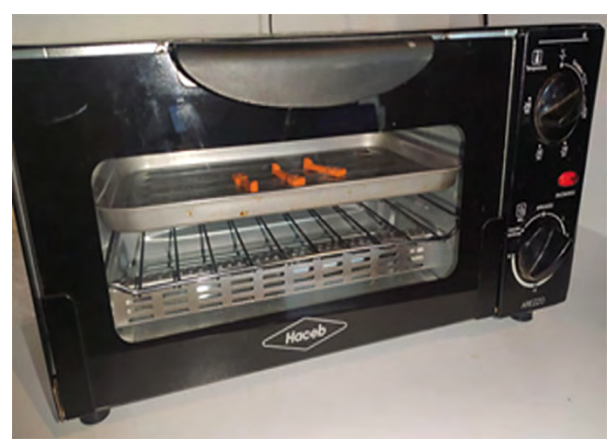

Figura 14. Proceso de tratamiento de las extremidades de la carcasa de eyección

Fuente: elaboración propia. 


\section{Estación terrena}

Con el objetivo de conocer el estado del CANSAT a lo largo de toda su misión, es necesario contar con una estación terrena capaz de recibir, procesar y graficar los datos tomados. Como se mencionó en la sección transceptor, la estación terrena cuenta con un módulo nRF24L01 con la tarjeta Arduino Uno. Para poder visualizar cómodamente los datos tomados por el CANSAT, se desarrolló una interfaz gráfica (GUI) en Python con librerías como Tkinter (Python, s. f.) y Matplotlib (Matplotlib, s. f.). Dicha interfaz gráfica las aceleraciones en los tres ejes coordenados del CANSAT y su altitud, $\mathrm{y}$ al mismo tiempo muestra los datos de humedad y rayos UV. De igual manera tiene la capacidad de mostrar el estado del sistema de recuperación indicando Off cuando no se ha accionado, y On cuando se accionó. Por medio de los datos de las aceleraciones, la interfaz determina la actitud del CANSAT, graficándola en 3D para una mejor visualización. En la figura 15 se muestra el CANSAT sin la estructura y la base terrena conectada a un PC, en el cual se puede ver la ventana principal de la interfaz gráfica. El esquema de comunicaciones se evidencia en la figura 16.

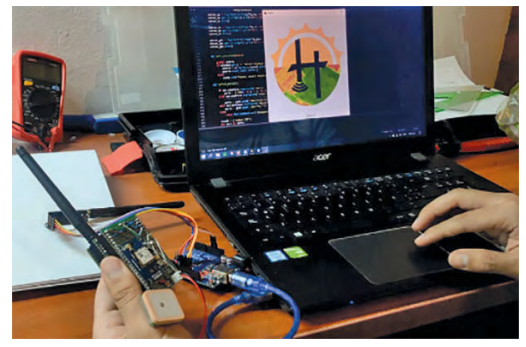

Figura 15. Comprobación de envío de datos con base terrena e interfaz gráfica

Fuente: elaboración propia.
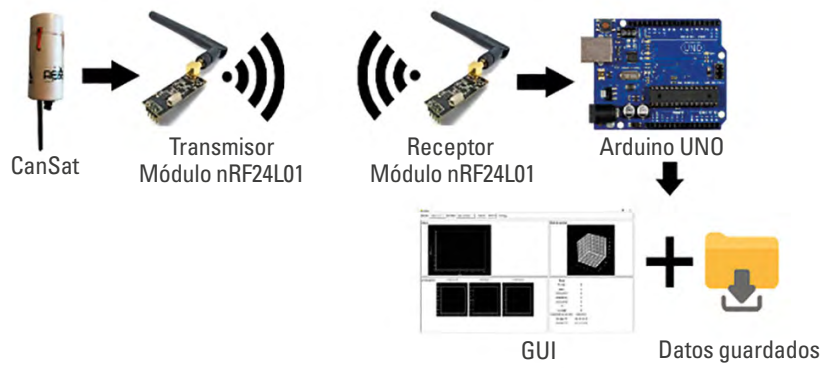

Figura 16. Funcionamiento del sistema de comunicaciones y telemetría Fuente: elaboración propia.

\section{Integración y prototipado}

Luego de tener la estructura, es necesario integrar los componentes descritos en la sección carga útil. Para esto se realizó un montaje preliminar (figura 17) con el objetivo de comprobar el funcionamiento de los componentes e integrar el algoritmo de la computadora de vuelo. Acto seguido se realizó un proceso optimización de espacio descrito a continuación.

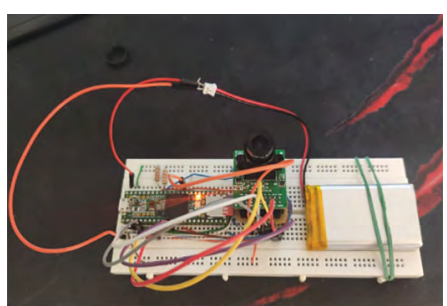

Figura 17. Montaje electrónico inicial para pruebas de funcionamiento Fuente: elaboración propia.

La integración de los componentes electrónicos fue posible gracias a un prototipado de dos capas en baquelita universal, lo cual facilitó la soldadura al disminuir el número de conexiones en una misma cara de la capa.

En la capa 1 se ubicaron los componentes que requerían cercanía a las paredes del CANSAT, es decir el módulo de comunicaciones, sensor de rayos UV y Teensy como se evidencia en la figura 18. Por otro lado, en la capa 2 se ubicaron los demás componentes como IMU, sensor de humedad y GPS (cara posterior) mostrados en la figura 19. Al momento de ensamblar ambas capas fueron unidas por medio del pin header macho y hembra de la cara 1 y cara 2 , respectivamente. El resultado final puede apreciarse en la figura 20.

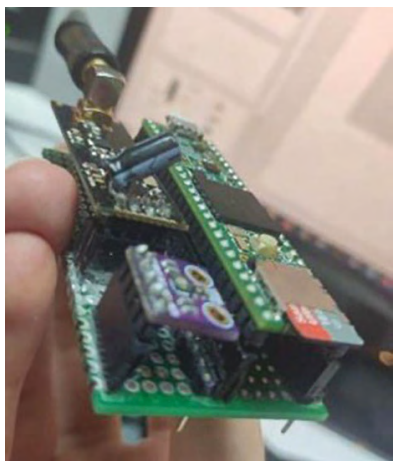

Figura 18. Capa 1 de integración de componentes Fuente: elaboración propia. 


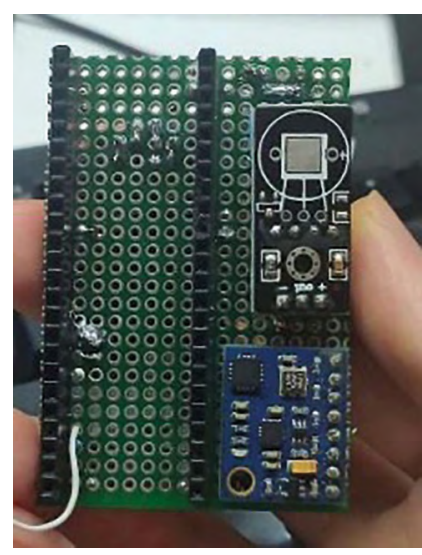

Figura 19. Capa 2 de integración de componentes Fuente: elaboración propia.

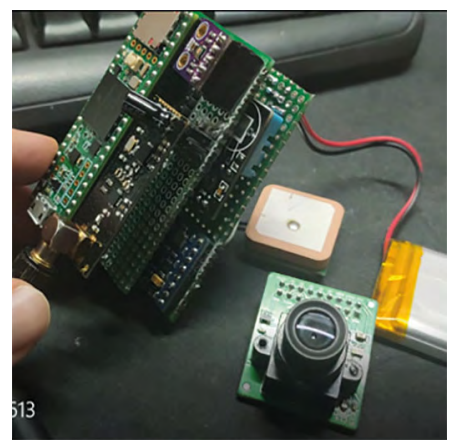

Figura 20. Prototipado final por capas

Fuente: elaboración propia.

Una vez se contó con todos los subsistemas terminados se procedió a integrarlos en un espacio de $120 \mathrm{~mm}$ de alto y $65 \mathrm{~mm}$ de diámetro, cumpliendo con los requerimientos. Para la disposición interna de los subsistemas en la parte superior del CANSAT se encuentra el sistema de recuperación y su mecanismo de eyección. Debajo de este, está la computadora de vuelo integrada con la carga útil y la potencia eléctrica. En la parte inferior del satélite se encuentra la antena y la cámara apuntando hacia abajo como se muestra en la figura 22, pues de esa manera la antena podrá transmitir de forma óptima a la base terrena y la cámara capturará imágenes de interés.

Para el ensamblado, primero se inserta tanto la antena como la cámara en la parte inferior, luego la computadora de vuelo y el resto de los sensores que hacen parte de las dos baquelas; después se introduce el resorte y la tapa superior con el paracaídas y finalmente se sella el satélite con los tornillos exteriores.

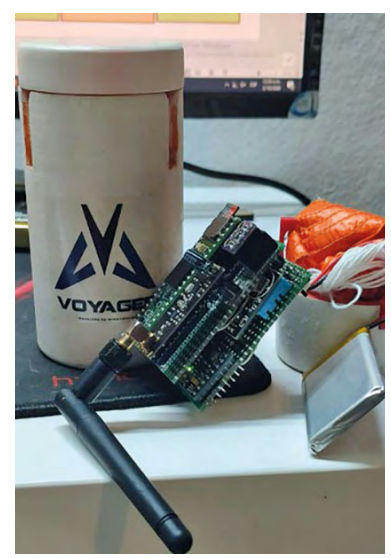

Figura 21. Integración final y sus componentes principales

Fuente: elaboración propia.

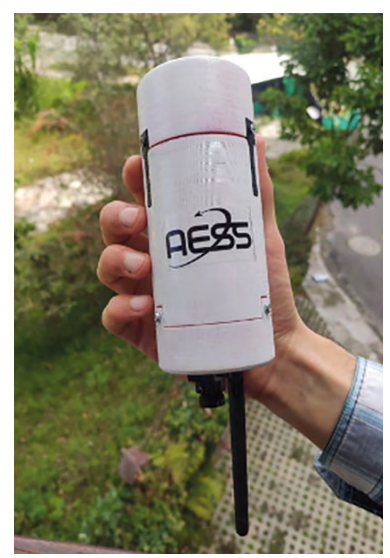

Figura 22. Vista exterior del CANSAT

Fuente: elaboración propia.

\section{Pruebas y resultados}

Con el objetivo de caracterizar y validar el CANSAT construido, se realizaron distintas pruebas a nivel funcional. Dada la naturaleza del prototipo y por simplicidad, las pruebas iniciales son poco rigurosas y de carácter cualitativo.

Así bien, con el fin de comprobar el funcionamiento del subsistema de navegación, el equipo trazó y recorrió un circuito de aproximadamente tres kilómetros. Con una precisión horizontal del modelo usado de aproximadamente 2,5 metros, en la figura 23 se muestran los resultados de esta prueba.

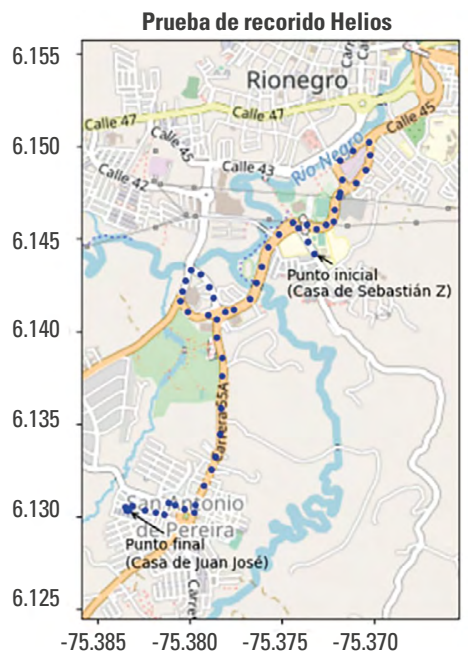

Figura 23. Gráfica de datos enviados por GPS

Fuente: elaboración propia. 
La carga útil junto con todos los subsistemas, se mantuvieron encendidos por lo menos una hora con el objetivo de comprobar que llegaban los datos medidos de cada uno de ellos a la estación terrena. Los sensores no sufrieron sobrecalentamientos ni intermitencias.

En cuanto a la telemetría, esta pudo enviar datos de tiempo, altitud, aceleración en los tres ejes y variables atmosféricas cada 0,2 segundos en las pruebas mencionadas. Asimismo, la base terrena tomaba dichos datos y los graficaba en tiempo real, indicando el estado de los sensores y del CANSAT en general. En la figura 24 se muestra una posición determinada del CANSAT con sus respectivos ejes coordenados de acuerdo con la disposición de la IMU dentro de la estructura, la figura 25 evidencia cómo las mediciones de aceleraciones corresponden con la posición descrita anteriormente, ya que se tienen valores cercanos a $1 G$ (una gravedad) para los ejes X y Z, pero para el eje Y se mantiene en cero.

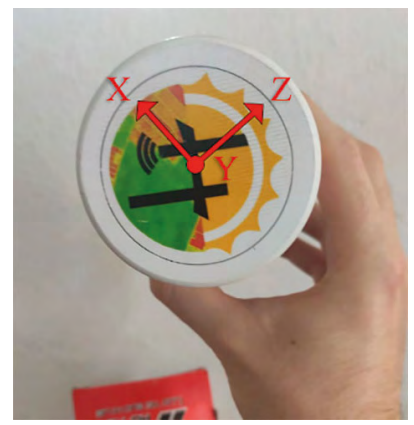

Figura 24. Comprobación de acelerómetro en el CANSAT Fuente: elaboración propia.
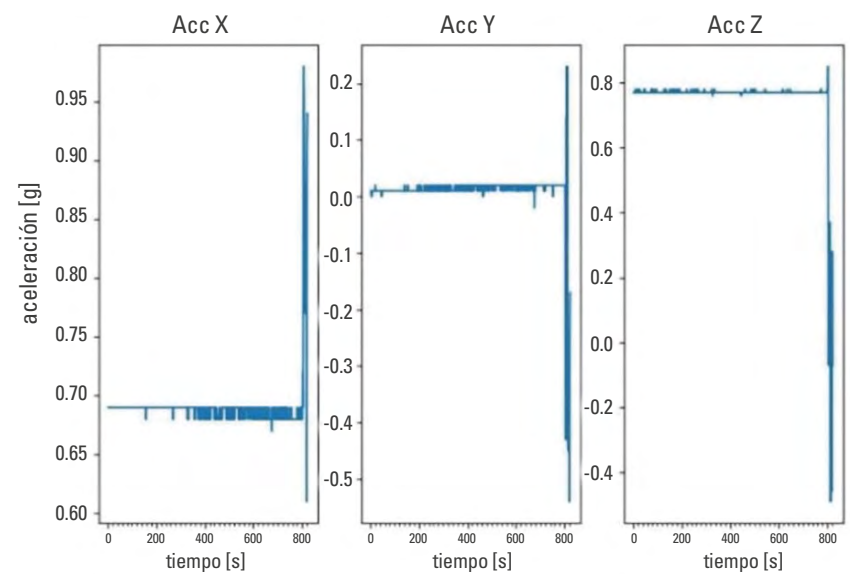

Figura 25. Aceleraciones en $X, Y$ y Z respecto al tiempo Fuente: elaboración propia.
Con el fin de verificar la capacidad de análisis de las imágenes que tomaría el CANSAT en su misión, se captó una imagen en la cual se muestra un cultivo de lechugas, como se puede ver en la figura 26 . Se realizaron pruebas del algoritmo de procesamiento de imágenes a partir de las imágenes adquiridas por la cámara, en este caso, para un cultivo de maíz. El resultado tras aplicar el índice ExG se ve en la figura 27, luego la imagen procesada se traspasa al espacio de color HSV, como se muestra en la figura 28. Los resultados muestran que el algoritmo es exitoso en identificar el verde de las plantas y permite el posterior análisis más complejo para actividades de agricultura de precisión.

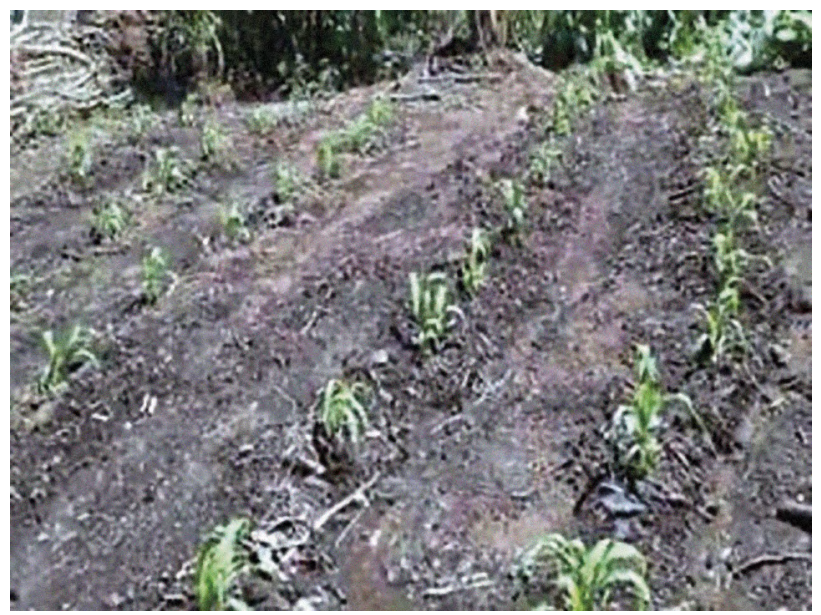

Figura 26. Imagen sin procesar de un cultivo de maíz Fuente: elaboración propia.

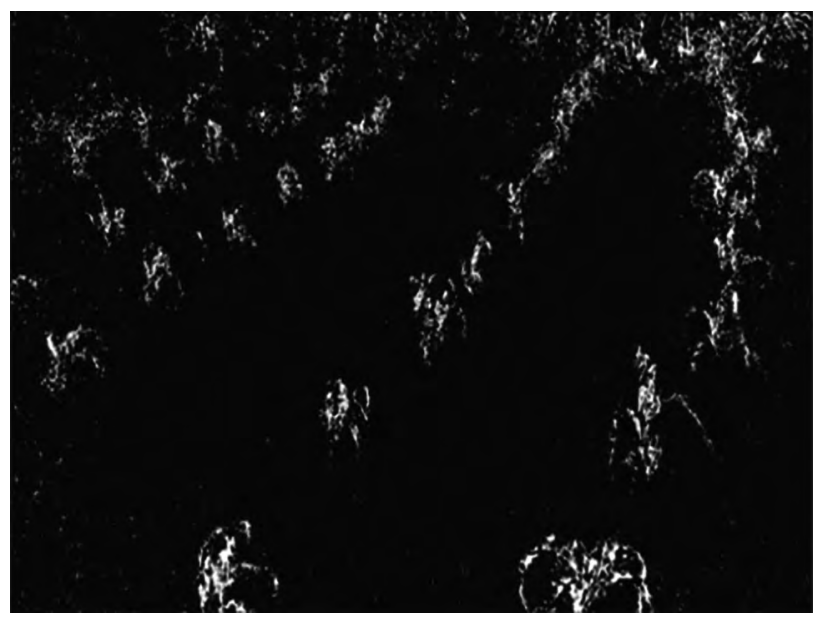

Figura 27. Imagen del cultivo con el índice ExG aplicado Fuente: elaboración propia. 


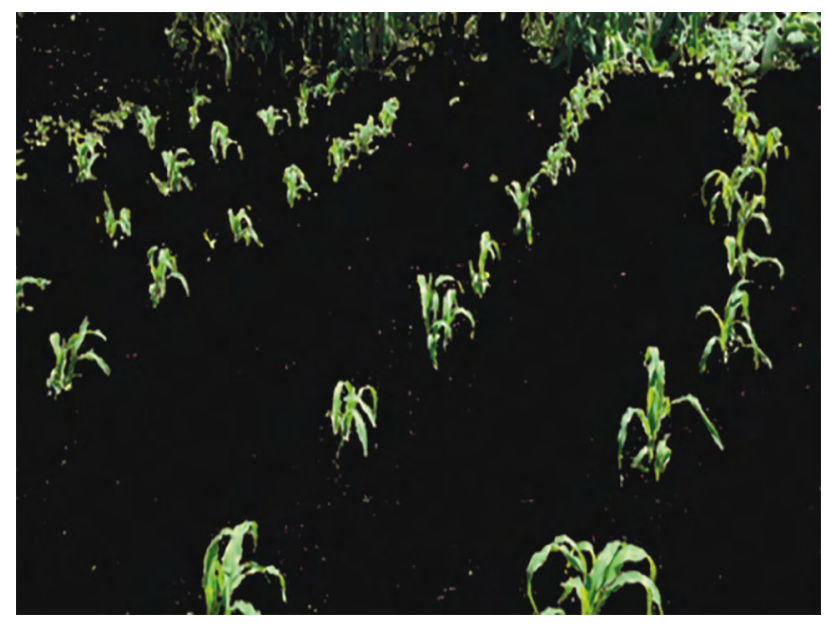

Figura 28. Imagen ExG en el espacio HSV

Fuente: elaboración propia.

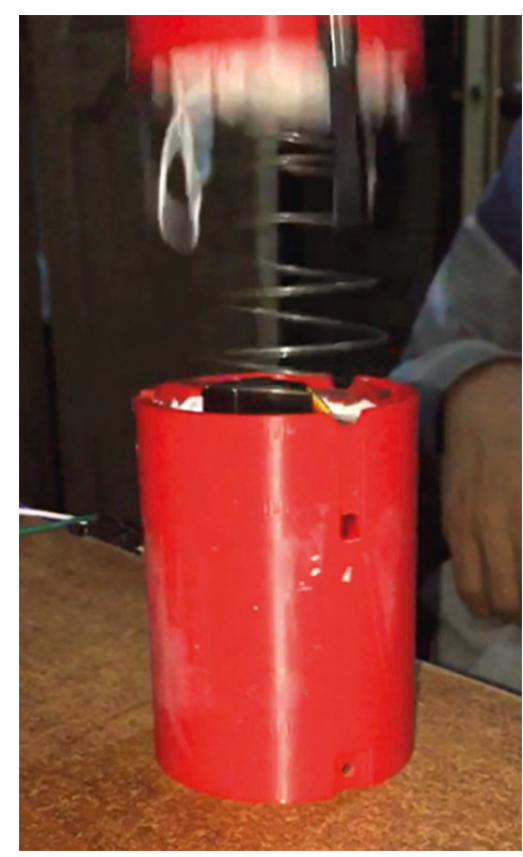

Figura 29. Prueba del sistema de eyección

Fuente: elaboración propia.

Por otro lado, para probar la estructura se dejó caer el satélite a tierra desde una altura aproximada de 6 metros, ya que la velocidad de impacto es cercana a la velocidad terminal descrita en la sección de descenso y recuperación. Esto para comprobar que la estructura impresa en 3D resistiera a un impacto semejante al que sufriría en un vuelo real. Se encontró que la estructura soportó las tres pruebas realizadas y no se presentaron daños.

Ahora bien, en cuanto al sistema de recuperación y descenso, se realizaron distintas pruebas, empezando por comprobar que el servomotor encargado de hacer girar el disco funcionara correctamente. Para esto, se ensambló el paracaídas junto con el resorte. Teniendo el CANSAT en la posición final, es decir, sellado con los tornillos, se accionó el servomotor mediante una señal programada en la tarjeta Arduino Uno. En la figura 29 se puede evidenciar la eyección de la tapa superior junto con el paracaídas.

Tabla 2

Presupuesto de masa, costo y potencia

\begin{tabular}{l|r|r|r}
\hline \multicolumn{1}{c|}{ Componente } & Peso [g] & Costo [USD] & Potencia [mW] \\
\hline Batería principal & 33,0 & 8,4 & 5.550 \\
\hline Baterías secundarias & 2 & 4 & 1.480 \\
\hline Microcontrolador & 4,8 & 49,5 & $-414,4$ \\
\hline IMU & 2,0 & 11,9 & -66 \\
\hline Sensor UV & 1,0 & 4,8 & -33 \\
\hline Cámara & 20,0 & 19,1 & -165 \\
\hline GPS & 5,0 & 5,9 & $-166,5$ \\
\hline Sensor humedad & 3,0 & 1,4 & $-1,65$ \\
\hline Transceptor & 9,0 & 3,8 & $-44,55$ \\
\hline Servo & 55,0 & 5,4 & -1.080 \\
\hline Paracaídas resorte & 33,0 & 16,2 & -- \\
\hline Estructura & 106,0 & 21,1 & -- \\
\hline Total & 273,8 & 151,5 & $1.971,1$ \\
\hline Margen & 226,2 & 98,5 & $5.058,9$ \\
\hline
\end{tabular}

Fuente: elaboración propia.

Finalmente, el presupuesto de masa, costo y potencia se muestra en la tabla 2, obteniendo un costo total de 151 USD, una masa de 274 gramos y un consumo de 1,9 W por parte de los componentes de la plataforma y la carga útil. Este consumo es provisto por las baterías que permiten un amplio margen de consumo de $5 \mathrm{~W}$ aproximadamente. 


\section{Conclusiones y observaciones}

Los sistemas CANSAT pueden ser empleados eficazmente como plataformas experimentales para realizar estudios académicos alrededor del área de la agricultura de precisión a bajo costo, frente a otras plataformas que no solo son más costosas sino más complejas de desarrollar. Por ello en etapas tempranas de investigación esta representa una opción viable.

La revisión de literatura arrojó sorpresivamente que existe un número muy limitado de trabajos alrededor del uso de CANSAT como mecanismos para el estudio y aprendizaje en agricultura de precisión. Esto último señala la necesidad de profundizar más en el área, lo cual puede representar una oportunidad para futuras investigaciones.

Es posible clasificar el resultado del diseño del CANSAT según el Technology Readiness Level (TRL) (Tzinis, 2015), una escala de la industria aeroespacial que mide el nivel de madurez, en este caso, tecnología en un nivel TRL 4, ya que el sistema se ha probado en tierra bajo condiciones similares de laboratorio donde se emula el perfil de vuelo del dispositivo, como lo fueron las pruebas descritas.

La implementación del algoritmo de procesamiento de imágenes proveyó gran potencial al CANSAT, en el sentido que permite analizar diferentes imágenes tomadas por él. Dicho software, al obtener el índice ExG puede ser utilizado no solo en cultivos, sino también en zonas en las cuales se requiera saber el nivel de vegetación e identificar enfermedades en plantas. Al integrar los datos atmosféricos medidos por el CANSAT, existe la posibilidad de prever posibles pérdidas en cultivos o zonas forestales realizando un diagnóstico más completo.

Las pruebas demostraron una funcionalidad plena de cada uno de los subsistemas y componentes del CANSAT. Cada sensor trabajó continuamente en pruebas de por lo menos una hora, sin sobrecalentamientos ni intermitencias, lo que indica que las conexiones de los circuitos no presentan cortos ni deficiencias en la soldadura.

A pesar de que el sensor GPS tardaba aproximadamente cinco minutos en recibir señal de los satélites, una vez lograba establecer la conexión era de forma continua. Así mismo, a lo largo de todas las pruebas la base terrena recibió y graficó los datos enviados por el CANSAT en la misma frecuencia que este los enviaba, demostrando que puede ser utilizada para diferentes tipos de CANSAT que desarrollen diversas misiones y envíen diferentes tipos de datos.

El mecanismo de eyección del subsistema de descenso y recuperación demostró ser confiable y de bajo costo, siendo así un sistema novedoso y de fácil implementación con la ventaja de ser versátil y poderse adecuar a otros CANSAT en los cuales su ensamble sea en la configuración de dos tapas.

Este trabajo fue realizado empleando metodologías de colaboración virtual debido a las restricciones públicas impuestas por la contingencia de la covid-19. Ello limitó la realización de pruebas en vuelo a fin de valorar su rendimiento. Pese a no haberlas realizado, los resultados permitieron verificar la funcionalidad plena del sistema. Se esperaría, una vez pase la emergencia sanitaria global, validar el rendimiento del sistema mediante pruebas más exhaustivas en campo.

Teniendo en cuenta el bajo costo de desarrollo y la compatibilidad con las tecnologías COTS, se abre la posibilidad de invertir e incorporar sensores de mejor resolución y otro tipo de variables que permitan análisis más especializados y de diferentes áreas del interés. Por lo anterior, es posible configurar estas plataformas como un dispositivo multipropósito.

Los CANSAT tienen potencial para ser explotados en apoyo a la investigación alrededor la agricultura de precisión y otras tecnologías emergentes, por ejemplo, al desarrollo de la industria 4.0 por su uso en sistemas embebidos, el procesamiento digital de imágenes y el Internet of Things (IoT).

\section{Agradecimientos}

Especiales agradecimientos a Santiago Vélez Casallas, quien desarrolló el código implementado en el CANSAT para agricultura de precisión. A los profesores, David Pineda y Jorge Elías Montoya, por su valioso apoyo 
durante el desarrollo del picosatélite, al semillero Voyager del programa de Ingeniería Aeroespacial y a su rama de agricultura de precisión. Por último, agradecemos a la corporación Cipsela por su apoyo y asesoría.

Declaración de conflicto de interés: Los autores no manifiestan conflictos de interés institucionales ni personales.

\section{Referencias}

Anchino, L. A., Torti, A. F., Dovis, E. M., Bernardi, E., \& Podadera, R. (2019). Implementación de una Plataforma de Desarrollo CANSAT Multipropósito. Elektron, 3(2), 120-127. https://doi.org/10.37537/rev.elektron.3.2.93.2019

Baran, E., Canbazoglu-Bilici, S., Mesutoglu, C., \& Ocak, C. (2019). The impact of an out-of-school STEM education program on students' attitudes toward STEM and STEM careers. School Science and Mathematics, 119(4), 223235. https://doi.org/10.1111/ssm.12330

Bhad, B., \& Akant, K. (2019). Experimental CANSAT for Measurment of UV Radiation. International Conference on Emerging Trends in Engineering and Technology, ICETET, 19-22. https://doi.org/10.1109/ICETET-SIP-1946815.2019. 9092213

Cabuya, G. (2020). Aerospace Colombia Ganadores CANSAT 2020. Colegio empresarial Los Andes.https://colegioem presarial.edu.co/aerospace-colombia-ganadores-CAN SAT-2020/

Cabuya, G. (2021, 30 de marzo). CANSAT 2020. AESS Colombia. https://aesscolombia.blogspot.com/p/CANSAT-colom bia-2020.html

Candiago, S., Remondino, F., De Giglio, M., Dubbini, M., \& Gattelli, M. (2015). Evaluating multispectral images and vegetation indices for precision farming applications from UAV images. Remote Sensing, 7(4), 4026-4047. https://doi.org/10.3390/rs70404026

Carrasco-Ríos, L. (2009). Efecto de la radiación ultravioleta-b en plantas. Idesia (Arica), 27(3), 59-76. https://doi.org/10.4067/S0718-34292009000300009

Centro de Investigación en Ciencias de Información Geoespacial [CentroGeo]. (s. f.). Percepción Remota. CentroGeo. https://www.centrogeo.org.mx/investigacion/ percepcion-remota

English, L. D., \& King, D. T. (2015). STEM learning through engineering design: fourth-grade students' investigations in aerospace. International Journal of STEM Education, 2(1), 1-18. https://doi.org/10.1186/s40594-015-0027-7

European Space Agency [ESA]. (s. f.). ESA - What is a CANSAT? http://www.esa.int/Education/CANSAT/What_is_a_ CANSAT

Faroukh, Y. M., AL-Ali, A. A. M. A., Adwan, A. O., Alhammadi, A., Shaikh, M. M., Faroukh, A. M., \& Femini, I. (2019, Ju(io). Environmental Monitoring using CANSAT. 2019 6th International Conference on Space Science and Communication (IconSpace) (pp. 239-244). IEEE. https://doi.org/10.1109/IconSpace.2019.8905942

Finagro. (2021). El momento del Agro. https://www.finagro. com.co/noticias/el-momento-del-agro

General Wire Spring Company. (s. f.). Conical compression springs. https://www.generalwirespring.com/conical-compression-springs.html

Honrado, J. L. E., Solpico, D. B., Favila, C. M., Tongson, E., Tangonan, G. L., \& Libatique, N. J. C. (2017). UAV imaging with low-cost multispectral imaging system for precision agriculture applications. GHTC 2017 - IEEE Global Humanitarian Technology Conference, Proceedings, 1-7. https://doi.org/10.1109/GHTC.2017.8239328

Jaramillo, O. A., \& Briñez, R. C. (2019). Design of a CANSAT for measuring environmental variables. Revista Especializada en Tecnología e Ingeniería, 13(2), 31-38. https://core.ac.uk/download/pdf/322589509.pdf

Matplotlib. (s. f.). Matplotlib: Visualization with Python. https://matplotlib.org/

Metternicht, G. (2003). Vegetation indices derived from high-resolution airborne videography for precision crop management. International Journal of Remote Sensing, 24(14), 2855-2877. https://doi.org/10.1080/01431160210163074

Molla, W. (2018). Design and development of CANSAT: Transmit weather data from troposphere level to the ground station. Addis Ababa University. http://213.55.95.56/bitstream/handle/123456789/15777/Waleligne\%20Molla. pdf? sequence=1\&isAllowed=y

Mouser Electronics. (s. f.). DHT11 Humidity \& Temperature Sensor [Archivo PDF]. https://www.mouser.com/datasheet/2/758/DHT11-Technical-Data-Sheet-Translated-Version-1143054.pdf

Nordic Semiconductor. (2008). nRF24 Single Chip Transceiver [Archivo PDF]. https://www.sparkfun.com/datasheets/ Components/SMD/nRF24L01Pluss_Preliminary_Product_Specification_v1_0.pdf 
OmniVision Technologies Inc. (s. f.). OV7670 Datasheet [Archivo PDF]. https://www.alldatasheet.com/datasheet-pdf/ pdf/312420/OMNIVISION/OV7670.html

Parody, A., \& Zapata, E. de J. (2018). Agricultura de precisión en Colombia utilizando teledetección de alta resolución. Suelos Ecuatoriales, 48(1-2), 41-49. http://unicauca.edu.co/revistas/index.php/suelos_ecuatoriales/article/view/94

PJRC. (s. f. a). Teensy 3,5 Development Board. https://www.pjrc. com/store/teensy35.html

PJRC. (s. f. b). Teensy Software Setup. https://www.pjrc.com/ teensy/tutorial.html

Python. (s. f.). Tkinter-Python interface to Tcl/Tk. https://docs. python.org/es/3/library/tkinter.html

Rodríguez, J. S., Botero, A. Y., Lopera, D. V., Gálvez, J., \& Botero, F. (2021). Experimental approach for the evaluation of the performance of a satellite module in the CANSAT form factor for in-situ monitoring and remote sensing applications. Hindawi International Journal of Aerospace Engineering, 1-31. https://www.hindawi.com/journals/ ijae/2021/8868797/

Sparkfun. (s. f.). Arduino Comparison Guide. https://www.sparkfun.com/advanced_arduino_comparison_guide

Tjandra, K. (2020). CANSAT 2020 Preliminary Design Review (PDR) Outline Team ID 1360. Manchester CANSAT Project. http://www.CANSATcompetition.com/docs/teams/CAN SAT2020_4920_pdr_v01.pdf
Tortora, P. G. (1996). Fairchild's Dictionary of Textiles. Bloomsbury Academic.

Trivelli, L., Apicella, A., Chiarello, F., Rana, R., Fantoni, G., \& Tarabella, A. (2019). From precision agriculture to Industry 4.0: Unveiling technological connections in the agrifood sector. British Food Journal, 121(8), 1730-1743. https://doi.org/10.1108/BFJ-11-2018-0747

Tzinis, I. (2015). NASA official website. https://www.nasa.gov/ directorates/heo/scan/engineering/technology/txt_accordion1.html

U-blox. (2017). NEO-6 u-blox 6 GPS Modules. U-blox, 25. https://www.u-blox.com/sites/default/files/products/ documents/NEO-6_DataSheet_(GPS.G6-HW-09005).pdf

Universidad Nacional Autónoma de México [UNAM]. (s. f.). ¿Qué es un CANSAT? Programa Espacial Universitario. http://peu.unam.mx/descripcionCANSAT.html

Vishay Semiconductors. (2019). Designing the VEML6070 UV Light Sensor. https://www.vishay.com/docs/84310/designingveml6070.pdf

Wertz, J. R., Everett, D. F., \& Pusschell, J. J. (2011). Space mission engineering: The new SMAD. Microcosm Press.

Yang, W., Wang, S., Zhao, X., Zhang, J., \& Feng, J. (2015). Greenness identification based on HSV decision tree. Information Processing in Agriculture, 2(3-4), 149-160. https://doi.org/10.1016/j.inpa.2015.07.003 